\title{
Oxidation of Ethanol and Its Derivates On Well Defined Pt Single Crystal Electrodes Vicinal to Pt(111): A Comparative Study
}

\author{
Rosa M. Arán-Ais ${ }^{\mathrm{a}}$, Nathalia Abe Santos ${ }^{\mathrm{b}}$, Hebe M. Villullas ${ }^{\mathrm{b}}$, Juan M. Feliu ${ }^{\mathrm{a}}$.

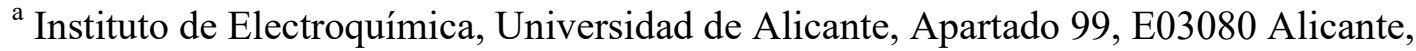 \\ Spain \\ ${ }^{\mathrm{b}}$ Instituto de Química, Universidade Estadual Paulista (UNESP), Rua Prof. Francisco \\ Degni 55, 14800-900 Araraquara, Brazil
}

\begin{abstract}
The oxidation of ethanol $(\mathrm{EtOH})$ at $\mathrm{Pt}(111)$ electrodes is dominated by the $4 \mathrm{e}$ path leading to acetic acid. The inclusion of surface defects such as those present on stepped surfaces leads to an increase of the reactivity towards the most desirable $12 \mathrm{e}$ path leading to $\mathrm{CO}_{2}$ as final product. This path is also favored when the methyl group is more oxidized, as in the case of ethylene glycol (EG) that spontaneously decomposes to $\mathrm{CO}$ on $\mathrm{Pt}(111)$ electrodes, thus showing a more effective breaking of the $\mathrm{C}-\mathrm{C}$ bond. Some trends in reactivity can be envisaged when other derivative molecules are compared at well-ordered electrodes. This strategy was used in the past, but the improvement in the electrode pretreatment and the overall information available on the subject suggest that relevant information is still missing.
\end{abstract}

\section{Introduction}

Ethanol (EtOH) oxidation in acidic media is a widely studied electrocatalytic reaction due to the increasing interest over the past years on the study of direct alcohol fuel cells using an acidic polymer electrolyte membrane. It deals with a complex problem that involves 12 e transfer steps before its complete conversion to $\mathrm{CO}_{2}$. The main drawback of this reaction for its application in fuel cells is the route to acetic acid (AcOOH) that preserves the integrity of the $\mathrm{C}-\mathrm{C}$ bond in the EtOH molecule [1]. The undesired path involves the transfer of only $4 \mathrm{e}$ and leads to a very stable final product that is difficult to decompose further without using particular strategies, e.g. using bacteria [2]. It has been shown that the best single metal electrocatalyst is platinum, its activity being improved after combining with $\mathrm{Ru}$ and $\mathrm{Sn}$ that can enhence the selectivity and/or the overall reaction rate $[3,4]$.

As other electrocatalytic processes, EtOH oxidation is a structure sensitive process. This means that the reactivity of the different paths depends on the different electrode surface structures used [5]. Among the platinum single crystal electrodes used, $\mathrm{Pt}(111)$ is the most reluctant to produce $\mathrm{CO}_{2}$, AcOOH being almost the only final product. It is known that $\mathrm{CO}_{2}$ can be produced only on the steps separating $\{111\}$ terraces and that the process involves the splitting of the $\mathrm{C}-\mathrm{C}$ bond in $\mathrm{CH}_{3}$ and $\mathrm{CH}_{2} \mathrm{OH}$ adsorbed residues [6]. The latter adsorbate rapidly leads to adsorbed $\mathrm{CO}$ while the former one would require higher potentials, likely involving the formation of oxygenated species in the step, to finally form adsorbed CO. In this respect, the adsorbed methyl group is stable enough to 
be a source for the formation of methane, a product reported from results given by Differential Electrochemical Mass Spectrometry (DEMS) studies [7].

Due to the complexity of the oxidation mechanism, more data are required to understand the reaction kinetics and thus have a hint to influence the surface reactivity towards the desired reaction. To simplify, it is convenient to study the problem on single crystal surfaces in which, at least ideally, a few types of surface sites are in contact with the solution side (e.g. one at the basal planes, two at stepped surfaces and three at kinked surfaces). Also, to point out the characteristics of these electrocatalytic processes, in which the surface plays a dominant role, it is useful to diminish the concentration of the species in solution, in such a way that all other contributions coming from transport controlled steps or, even worse, kinetically controlled processes, could be minimized. In this communication we have tried to diminish reactant concentration in order to isolate the processes taking place at the surface as much as possible from other concentration dependent processes.

Another approach to the understanding of EtOH oxidation would be the study of reactivity of similar molecules, such as ethylene glycol (EG) and glycolic acid (GA). In both cases, the $\mathrm{CH}_{3}$ group has been partially oxidized, either in relation to the reactant $(\mathrm{EtOH})$ or to the product $(\mathrm{AcOOH})$. It is known that $\mathrm{EG}$ extensively breaks the $\mathrm{C}-\mathrm{C}$ bond and produces adsorbed $\mathrm{CO}$ as practically the only surface residue [8]. On the other hand, this inclusion of an $\mathrm{OH}$ group also induces reactivity to glycolic acid, which can be oxidized at reasonably low potentials [9]. A key step to activate EtOH oxidation might be to partially oxidize the methyl group of the EtOH molecule. To maintain the general experimental approach, low concentrations of these more oxidized compounds are used in order to favor the surface reaction related steps.

\section{Experimental}

Platinum single crystal electrodes were used as working electrodes. They were made by fusion and subsequent slow crystallization of a $99.999 \%$ platinum wire, which after careful cooling, were cut and polished following the procedure described in Ref. [10]. Before each experiment, the single crystal electrodes were flame-annealed for around 10 $\mathrm{s}$ in a gas-oxygen flame, cooled down in a reductive atmosphere $\left(\mathrm{H}_{2}+\mathrm{Ar}\right.$ at a 1:3 ratio) and quenched in ultrapure water in equilibrium with this atmosphere before transferring to the electrochemical cell. Experiments were performed at room temperature in a classical two-compartment electrochemical cell, de-aerated using argon (Air Liquid, N50). The counter electrode was a platinum wire and the potentials were measured against a reversible hydrogen (Air Liquid, N50) electrode (RHE) connected to the cell through a Luggin capillary. Solutions were prepared from perchloric acid (Merck Suprapur ${ }^{\circledR}$ ), ethanol (Merck p.a.), ethylene glycol (Merck p.a.) and glycolic acid (Sigma Aldrich, 99\%) in ultrapure water from Elga. The electrode potential was controlled using an EG\&G PARC 175 signal generator in combination with an eDAQ EA 161 potentiostat and currents were recorded using an eDAQ e-corder ED401 recording system.

The characterization of the poisoning intermediate (PI) on EG oxidation was carried out using a flow cell, which in addition of the components of classical electrochemical cell, it is provided with an inlet through which the supporting electrolyte is circulated into the cell and a outlet through which the solution can be removed. Prior to the poison formation, a blank voltammogram in perchloric acid was recorded in order to check the cleanliness of the system, as well as to measure the initial amount of adsorbed hydrogen. 
After the blank was recorded, the flow cell was filled with the EG containing acidic solution. The poison was formed by immersing the working electrode for 2 minutes at a controlled potential of $0.3 \mathrm{~V}$. After that, the inlet of supporting electrolyte and the outlet of the flow cell were opened, inducing the output of the EG solution, the cleaning of the cell, and the renewal of the electrolyte solution, always keeping the electrode immerged, in such a way that its potential is ever controlled. Finally, a complete cycle in the hydrogen adsorption/desorption potential range was applied in order to evaluate the amount of remaining poison-free platinum sites. Once this cycle was completed, poison oxidation was carried out in a single excursion up to $0.9 \mathrm{~V}$, recorded at the same sweep rate. The recovery of hydrogen adsorption ability of the surface was determined in the subsequent cycle in the complete range of potential.

\section{Results and Discussion}

\section{Ethanol oxidation}

Effect of ethanol concentration. Fig. 1 shows a comparison of cyclic voltammograms taken at $50 \mathrm{mV} \mathrm{s}^{-1}$ in $0.1 \mathrm{M} \mathrm{HClO}_{4}$ solutions with different EtOH concentrations for the $\mathrm{Pt}(111)$ electrode. At the lowest EtOH concentration used in this study $\left(10^{-5} \mathrm{M}\right)$ the hydroxyl $(\mathrm{OH})$ adsorption-desorption appears broaden and slightly shifted towards more positive potentials at the time that a small and broad peak of cathodic current centered at c.a. $0.52 \mathrm{~V}$ is observed in the negative-going scan. The overall voltammogram looks similar to those observed with $\operatorname{Pt}(111)$ electrodes in slightly contaminated perchloric acid solutions, although in the present case the "contamination" is the intentionally added $10^{-5}$ $\mathrm{M} \mathrm{EtOH}$. Increasing the ethanol concentration up to $10^{-4} \mathrm{M}$ allows observing an ethanol oxidation peak at about $0.65 \mathrm{~V}$ while the $\mathrm{OH}$ adsorption-desorption process is not longer apparent. The negative scan shows an increase in the cathodic peak observed at $0.52 \mathrm{~V}$. Besides the expected increase in the oxidation peak of the positive scan, further increase of the ethanol concentration $\left(5 \times 10^{-4} \mathrm{M}\right)$ shows positive currents in the negative sweep in the $0.87-0.55 \mathrm{~V}$ potential range and a decrease in the cathodic current peak at $0.52 \mathrm{~V}$. This cathodic peak is no longer seen in the curve taken in $10^{-3} \mathrm{M}$ ethanol that above $0.4 \mathrm{~V}$ shows only positive currents.

The appearance of a broad cathodic peak in the negative sweep at approximately 0.55 $\mathrm{V}$ was reported by Cases et al. [11] in their studies of the voltammetric behavior of adsorbed residues resulting from the adsorption of acetaldehyde and ethanol on a $\operatorname{Pt}(111)$ electrode. The results of those studies showed that the broad cathodic peak is due to an anion with two carbon atoms (acetate anion). Lai and Koper [12] made voltammetric measurements in $0.1 \mathrm{M}$ acetic acid solution for single-crystal electrodes of $\mathrm{Pt}$ $[\mathrm{n}(111) \mathrm{x}(111)]$ and observed a broad process extending from 0.3 to about $0.9 \mathrm{~V}$, which was attributed to the adsorption of acetic acid (acetate). They also showed that the adsorption of acetate is stronger than the adsorption of (bi)sulfate. Accordingly, the voltammetric curves shown in Fig. 1 demonstrate that the acetic acid formed in the electrochemical oxidation of ethanol adsorbs as acetate anions causing a broadening of the $\mathrm{OH}$ adsorption process. At very low concentrations acetate desorption is seen as a broad reduction peak around $0.52 \mathrm{~V}$. As the ethanol concentration increases, larger amounts of acetic acid are formed that hold back further the $\mathrm{OH}$ adsorption process. Because there are larger amounts of species that can be oxidized, the currents measured on the negative sweep result from ethanol oxidation on sites that become progressively 

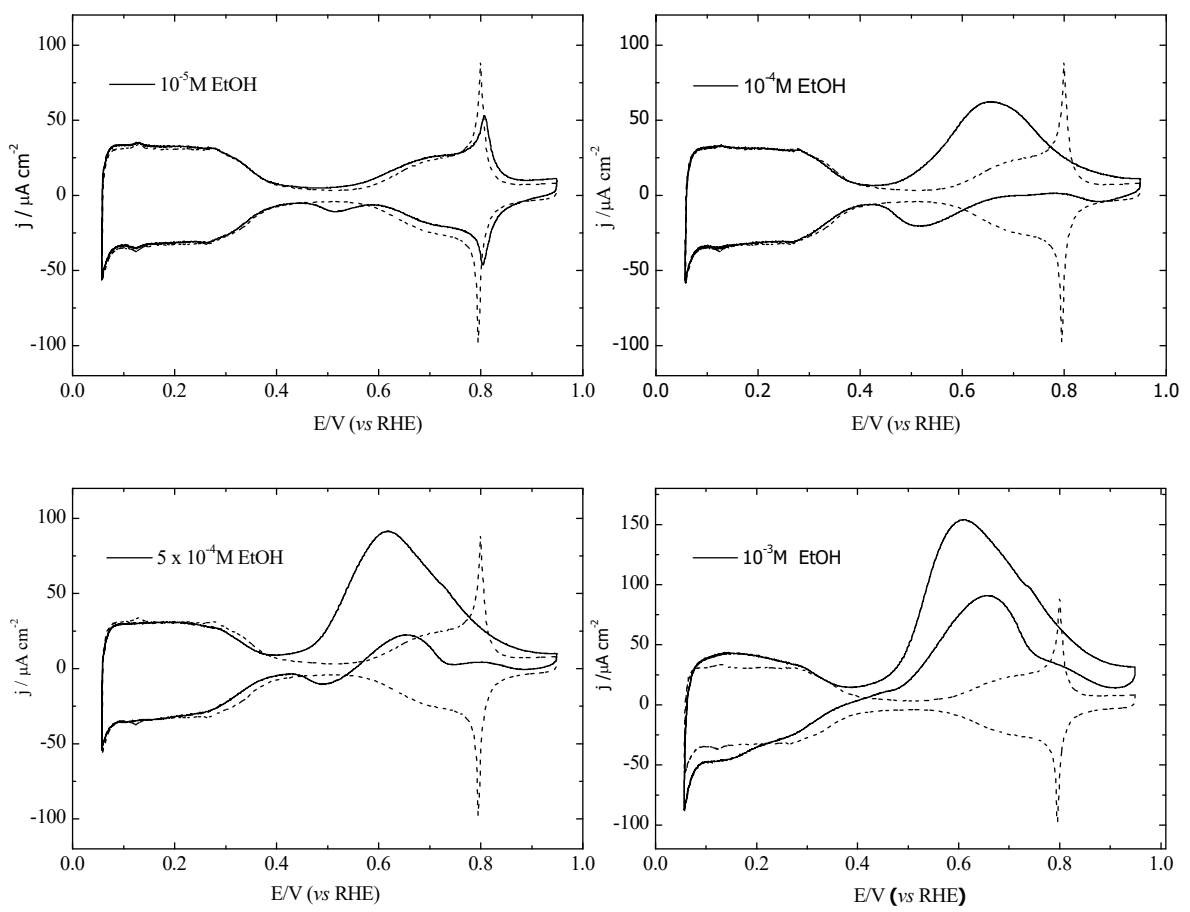

Figure 1. Voltammetric curves (second cycle) for $\mathrm{Pt}(111)$ in $0.1 \mathrm{M} \mathrm{HClO}_{4}$ (dashed line) and different ethanol molar concentrations (solid line), as indicated. Sweep rate: $50 \mathrm{mVs}^{-1}$.

available as desorption of $\mathrm{OH}$ and acetate take place. It is interesting to note that in $10^{-4} \mathrm{M}$ ethanol, acetate desorption appears to be the process that contributes the most to the current measured in the negative potential scan. In contrast, for the two largest concentrations $\left(5 \times 10^{-4}\right.$ and $\left.10^{-3} \mathrm{M}\right)$ the oxidation reactions become dominant and mask the surface limited desorption of acetate. For these two ethanol concentrations, the oxidation current observed in the negative scan involves two distinct processes leading to the increase of available Pt sites for ethanol oxidation. The shoulder observed at about 0.8 $\mathrm{V}$ seems to be related to the oxidation of ethanol on the Pt sites from which $\mathrm{OH}_{\mathrm{S}}$ is desorbed, while the peak at lower potentials is connected to the oxidation occurring on sites available as desorption of $\mathrm{OH}_{\mathrm{B}}$ takes place [13]. It should be realized that EtOH oxidation can take place in solutions containing specifically adsorbed anions, although at higher potentials and involving smaller currents than in perchloric acid.

Similar experiments were done on stepped surfaces $\operatorname{Pt}(n, n, n-2)$ having different amounts of (111) terraces and (110) monoatomic steps as junctions of (111)x(111) microfacets [10]. The blank voltammograms recorded in perchloric acid are depicted in Fig. 2, which shows the gradual appearance of the sharp peak at $0.13 \mathrm{~V}$ typically observed on $\mathrm{Pt}(110)$, as the number of (110) steps increases.

In a general manner, the curves measured for the stepped surfaces in $0.1 \mathrm{M} \mathrm{HClO}_{4}$ solutions containing low ethanol concentrations show features similar to those observed for the Pt(111) electrode. Fig. 3 shows the comparison of voltammograms obtained for the different electrodes. It is observed on Figs. 3A and B that the acetate desorption peak shifts towards more positive potentials as the amount of (110) steps increases, indicating 
that acetate adsorption is somewhat surface-sensitive and weaker on the steps. These differences are likely to be the cause of the variations of EtOH oxidation currents seen in Figs.3C and D.

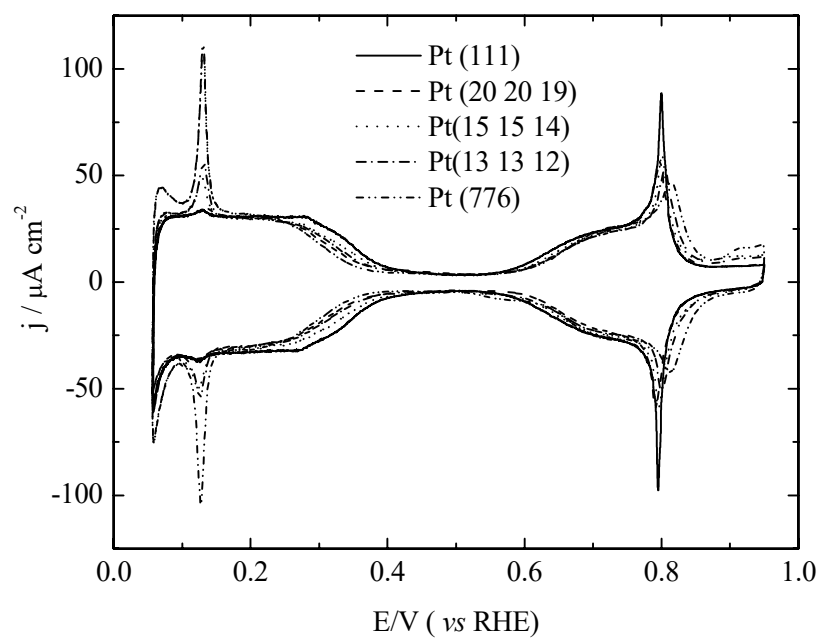

Figure 2. Cyclic voltammograms recorded in $0.1 \mathrm{M} \mathrm{HClO}_{4}$ for $\mathrm{Pt}(111)$ and electrodes with stepped surfaces, as indicated. Sweep rate: $50 \mathrm{mV} \mathrm{s}^{-1}$.
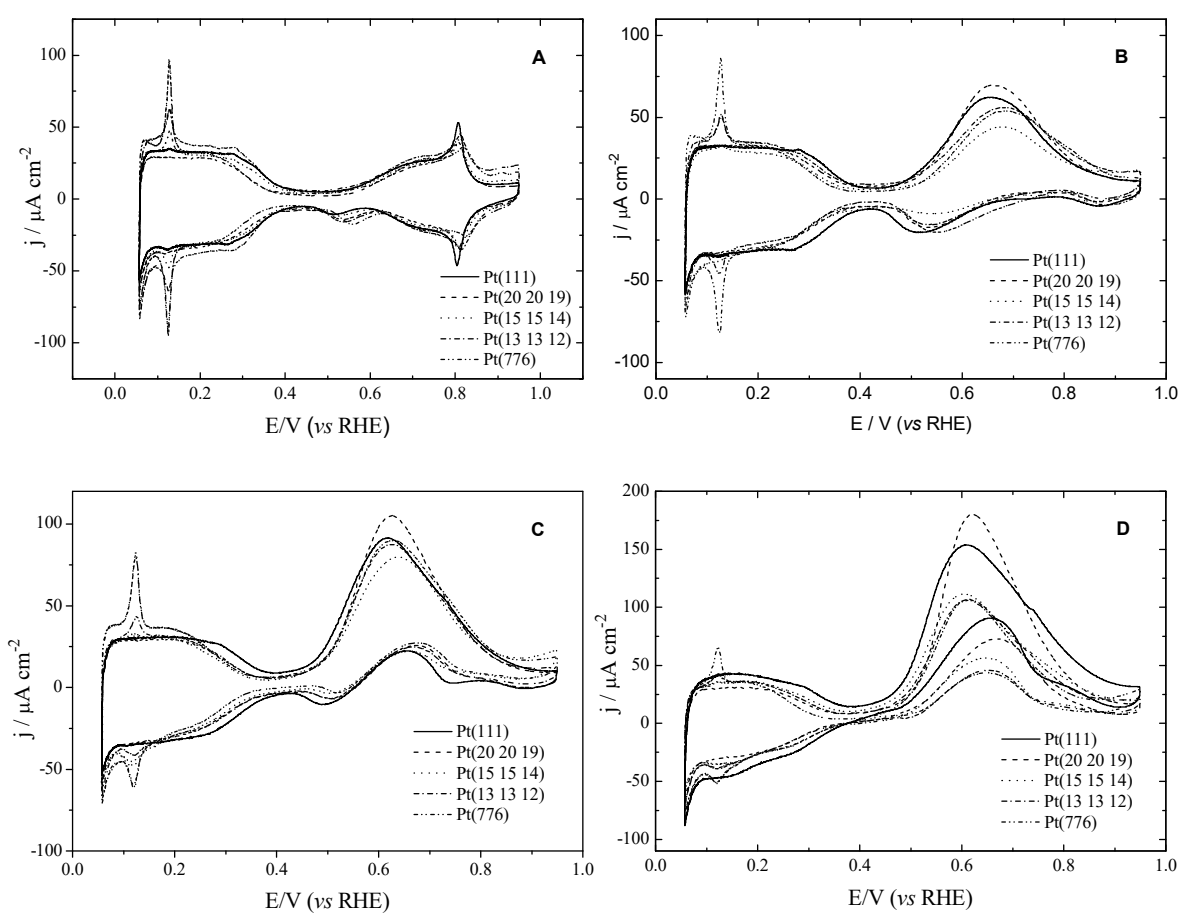

Figure 3. Cyclic voltammograms recorded for $\mathrm{Pt}(111)$ and electrodes with stepped surfaces, as indicated, in $0.1 \mathrm{M} \mathrm{HClO}_{4}+\mathrm{EtOH}$ : A) $10^{-5} \mathrm{M}$, B) $\left.10^{-4} \mathrm{M}, \mathrm{C}\right) 5 \times 10^{-4} \mathrm{M}$, and D) $10^{-3} \mathrm{M}$. Sweep rate: $50 \mathrm{mV} \mathrm{s}^{-1}$. 


\section{Ethylene Glycol oxidation}

The oxidation of ethylene glycol in acidic media to $\mathrm{CO}_{2}$ is a 10 e process. This complex reaction involves several consecutive and parallel reaction steps, leading to different reaction intermediate products. In the reaction path where the $\mathrm{C}-\mathrm{C}$ bond is not altered, glycolaldehyde, glyoxal, glycolic acid, glyoxylic acid and oxalic acid, before yielding $\mathrm{CO}_{2}$, have been identified as reaction products $[14,15]$. In addition, the $\mathrm{C}-\mathrm{C}$ bond in each intermediate product can also break (at a different rate), producing monocarbon species, as formic acid and formaldehyde $[15,16]$.

Fig. 4 presents the voltammetric profiles of ethylene glycol (EG) oxidation at Pt single crystals electrodes. Within the basal planes, the $\operatorname{Pt}(111)$ electrode shows the best electrocatalytic properties. Although the $\operatorname{Pt}(110)$ and $\operatorname{Pt}(100)$ electrodes exhibit higher peak currents, the $\operatorname{Pt}(111)$ electrode has the lowest onset potential for the oxidation of EG. The small difference in currents between the positive and the negative direction scans reveals that $\operatorname{Pt}(111)$ also has the lowest poisoning rate by CO. Similar behavior was found for ethanol oxidation [17,18]. However, when working with such high concentrations, e.g. 0.1 M EG, the surface is saturated with adsorbed species that continuously come from the bulk solution, adsorb and react, generating high faradic currents that make difficult to distinguish between the contributions due to the adsorption of the different species and their oxidation in the reaction layer close to the surface.

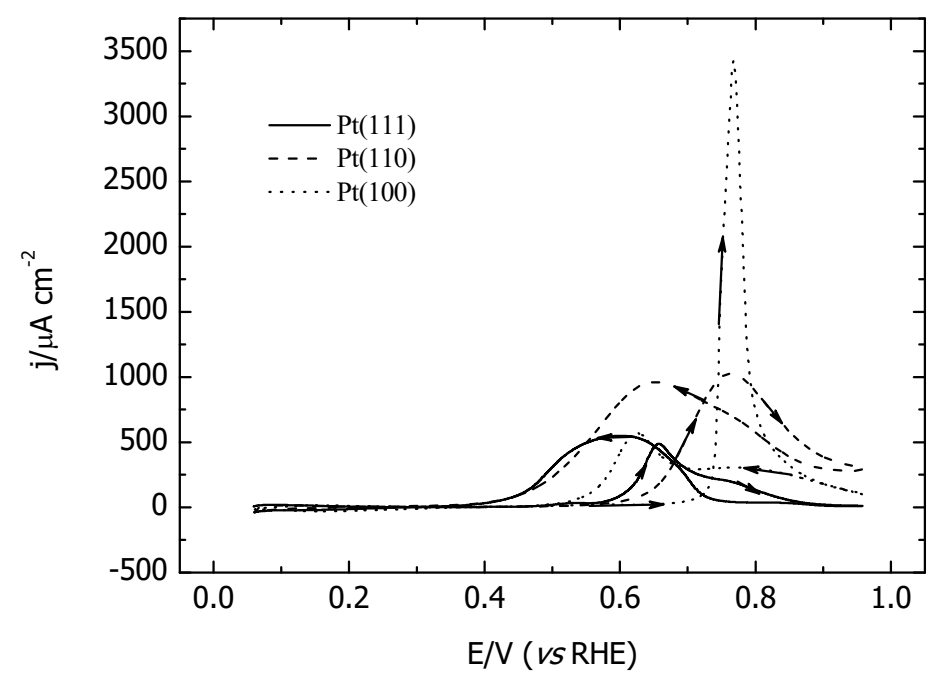

Figure 4. Stationary voltammetric profiles for the oxidation of $0.1 \mathrm{M} \mathrm{EG}$ in $0.1 \mathrm{M} \mathrm{HClO}_{4}$ solution on the basal planes. Sweep rate, $50 \mathrm{mV} \mathrm{s}^{-1}$.

The aim of this work was to use low concentrated solutions of EG in order to enable the identification of the different phenomena that take place at the surface of the electrode and its relation with its structure. In this approach, Fig. 5A shows the voltammetric hydrogen adsorption/desorption profile of the $\mathrm{Pt}(111)$ in perchloric acid (dashed line) and that obtained for a $10^{-5} \mathrm{M} \mathrm{EG}$ in $0.1 \mathrm{M} \mathrm{HClO}_{4}$ solution (solid line). It can be seen that, for a low concentration of EG, the hydrogen adsorption region is not altered. The small differences that are observed between the two curves might be due to the different contact of the electrode with the solution, taking into account that the surface tension changes in 
the absence or presence of EG. Besides the hydrogen adsorption, three main features can be observed in the positive scan in the presence of EG, at $0.58,0.72$ and $0.80 \mathrm{~V}$. The latter one is associated to the $\mathrm{OH}$ adsorption, as it matches with the peaks of the blank, already assigned to the adsorption of this anion. This means that the processes that take place at lower potentials do not affect the $\mathrm{OH}$ adsorption on the $\mathrm{Pt}(111)$. Fig. 5B represents the subtraction of the blank to the $10^{-5} \mathrm{M}$ EG oxidation curve, in order to differentiate the contributions due to the adsorption/desorption of the ions of the supporting electrolyte and those from the EG. In the positive scan (solid line), the signal that appears at $0.3 \mathrm{~V}$ is due to the adsorption of specie(s), while those above $0.6 \mathrm{~V}$ are related to the EG oxidation. It should be noticed that the butterfly peak associated to the $\mathrm{OH}$ adsorption on $\mathrm{Pt}(111)$ is partially blocked both in the positive and negative going sweeps, indicating the presence of other specie(s) on the surface that inhibit $\mathrm{OH}_{\mathrm{S}}$ adsorption. When current in the negative scan is considered, small hysteresis can be noticed in the region where the oxidation of EG takes place. In addition, the desorption of an anion is observed at $0.47 \mathrm{~V}$ (it might be adsorbed glycolate) and the hydrogen adsorption region is partially blocked.

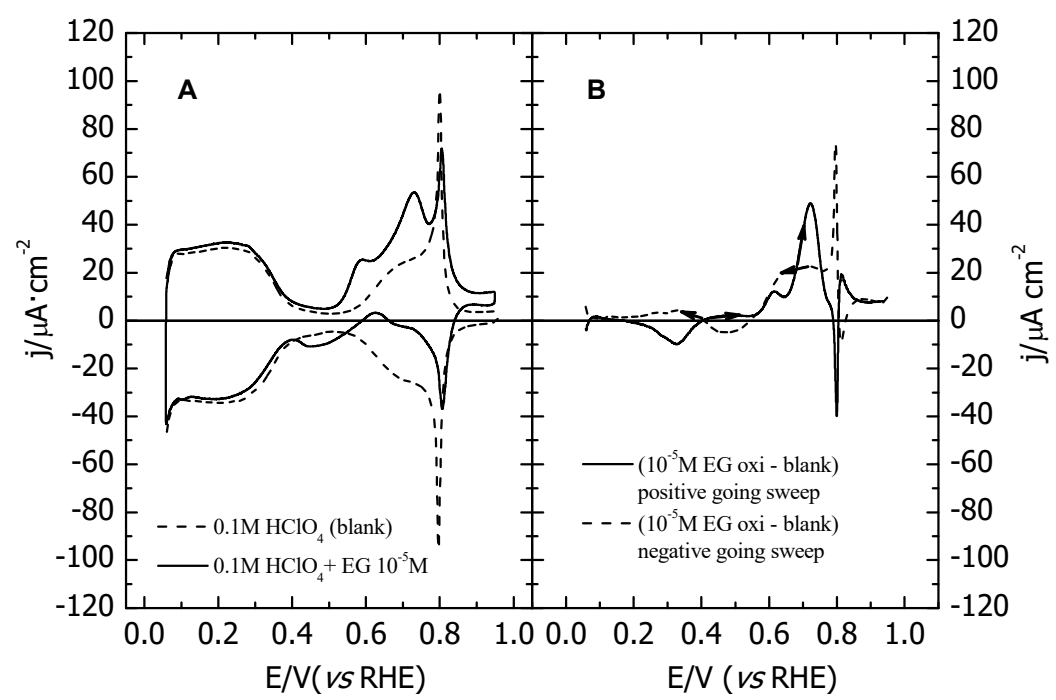

Figure 5. (A) Stationary voltammetric profile of $\mathrm{Pt}(111)$ in $0.1 \mathrm{M} \mathrm{HClO}_{4}$ (dashed line) and for the oxidation of $10^{-5} \mathrm{M} \mathrm{EG}$ in $0.1 \mathrm{M} \mathrm{HClO}_{4}$ solution (solid line). (B) Curves corresponding to the oxidation of $10^{-5} \mathrm{M} E \mathrm{E}$ in $0.1 \mathrm{M} \mathrm{HClO}_{4}$ on $\mathrm{Pt}(111)$ subtracted by the blank: positive going sweep (solid line) and negative going sweep (dashed line). Sweep rate, $50 \mathrm{mV} \mathrm{s}^{-1}$.

The oxidation of $10^{-5} \mathrm{M}$ EG solution was carried out embracing different potential windows. Fig. 6 displays the results recorded. When the $\mathrm{Pt}(111)$ electrode is cycled up to $0.4 \mathrm{~V}$, it is observed a decrease in the charge involved in the hydrogen adsorption region, which agrees with the information extracted from Fig. 5B, e.g. something is attaching and blocking the surface of the electrode. When the potential range moves up to $0.6 \mathrm{~V}$, a small oxidation process appears, likely involving adsorbed $\mathrm{CO}$ at low coverage. When cycling to higher potentials, a desorption feature appears at $0.47 \mathrm{~V}$ in the negative going sweep, becoming higher if the potential is hold at $0.75 \mathrm{~V}$ for a few seconds. The hydrogen adsorption/desorption region is recovered when the electrode is cycled to $0.95 \mathrm{~V}$, and a reversible peak at $0.1 \mathrm{~V}$ appears, which is related to the adsorption/desorption of hydrogen on steps with symmetry (110). 


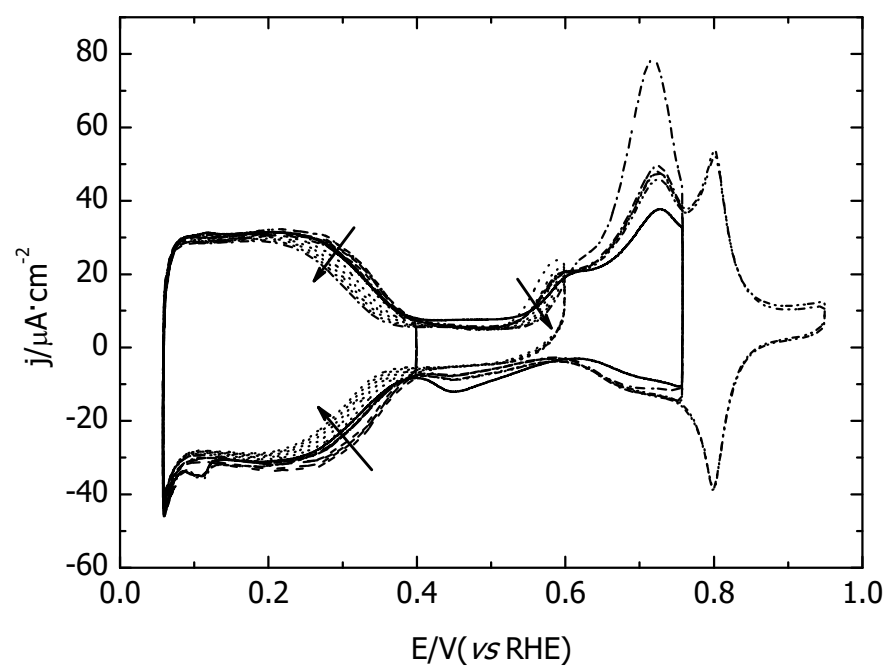

Figure 6. Voltammetric oxidation on $\mathrm{Pt}(111)$ of $10^{-5} \mathrm{M}$ EG in $0.1 \mathrm{M} \mathrm{HClO}_{4}$. Sweep rate, $50 \mathrm{mV} \mathrm{s}^{-1}$.

Experiments using the flow cell were carried out with the purpose of extract more information about the poisoning intermediate (PI) and the features that appear on the EG oxidation curves at low concentrations. The knowledge of the generation processes of PI and its electrochemical behavior is one of the key steps to achieve better control of the electrooxidation mechanism of small organic molecules to obtain better efficiency of the catalyst. The oxidation of the accumulated poison on the $\operatorname{Pt}(111)$ surface for $10^{-3} \mathrm{M}$ EG solution (Fig. 4) shows the same characteristic profile as obtained in similar experiments with the poison formed from formic acid [19] and methanol [20], e.g. adsorbed CO.
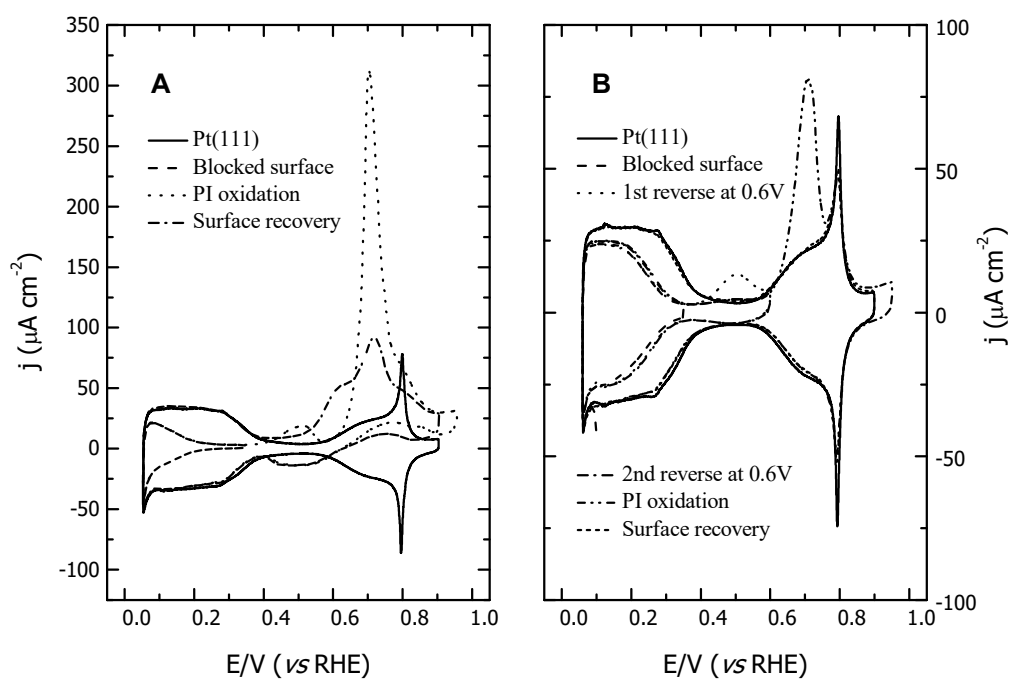

Figure 7. Voltammetric oxidation on $\mathrm{Pt}(111)$ of the poisoning intermediate (PI) formed by dissociative adsorption of EG at $0.3 \mathrm{~V}$. Test solution: (A) $0.1 \mathrm{M} \mathrm{EG}$ in $0.1 \mathrm{M} \mathrm{HClO}_{4}$. (B) $10^{-3} \mathrm{M} \mathrm{EG}$ in $0.1 \mathrm{M} \mathrm{HClO}_{4}$. Sweep rate, $50 \mathrm{mV} \mathrm{s}^{-1}$. 
On a first approach of the experiment, a $0.1 \mathrm{M} \mathrm{EG}$ in $0.1 \mathrm{M} \mathrm{HClO}_{4}$ solutions was used to the formation of the poison (Fig. 7A). By considering the differences in the voltammograms before PI formation and after PI oxidation, it may be concluded that the EG has not been completely removed from the cell, and a curve similar to that obtained in Fig. 6 is observed. This means that a small amount of organic residue is still present in the cell, and this is the cause why curves are not superimposed. For that reason, a more diluted solution of EG was used in further experiments with the flow cell (Fig. 7B). In that case, the blocking of the surface in the hydrogen region is not as pronounced as in the more concentrated EG solution, but the same features can be observed: a peak at $0.50 \mathrm{~V}$ that does not appear in the following cycle, and a peak at $0.7 \mathrm{~V}$. When a diluted solution is used to for the formation of the PI, it is possible to completely remove the EG from the cell and after the PI oxidation, and thus the blank of the surface in the supporting electrolyte is recorded, although the intensity of the butterfly peaks slightly decrease.

With that information is possible to conclude that the $\mathrm{CO}$, produced by spontaneous dissociation of the EG in contact with the platinum, is responsible for the partial blocking of the surface at lower potentials. The adsorbed $\mathrm{CO}$ is oxidized to $\mathrm{CO}_{2}$ at $0.58 \mathrm{~V}$ and $0.78 \mathrm{~V}$, likely as isolated molecules and more compact islands, respectively. In this experiments, no species are observed that desorb in the negative scan thus pointing out to different time scales between $\mathrm{CV}$ and PI analysis experiments.

\section{Glycolic Acid oxidation}

The reactivity of glycolic acid is expected to be like that showed by acetic acid due to the similarity of their molecular structures. In fact, the voltammetric profile of $\mathrm{Pt}(111)$ in a $0.1 \mathrm{M} \mathrm{GA}+0.1 \mathrm{M} \mathrm{HClO}_{4}$ solution is quite similar to those obtained for solutions of acetic acid [21,22] and oxalic acid [23] with the same concentration, which is typical of a reversible anion-like adsorption. Nevertheless, the presence of a $\mathrm{OH}$ group in the molecule of glycolic acid makes it more reactive. So, besides the adsorption of the glycolate, which is a thermodynamically controlled process, is also possible to differentiate a kinetic process in the cyclic voltammetry, associated to the reaction of the GA. Fig. 8 shows the influence of the sweep rate on this kinetic processes, which take place above $0.6 \mathrm{~V}$, while the hydrogen adsorption region (below $0.37 \mathrm{~V}$ ) and the anion adsorption (broad state around $0.45 \mathrm{~V}$ ) are not affected after sweep rate normalization.

With the purpose of discern the contributions due to anion adsorption/desorption processes to those from GA oxidation, the results displayed on Fig. 8 where submitted to a mathematical treatment. First of all, a voltammogram of the Pt(111) electrode on $0.1 \mathrm{M}$ $\mathrm{HClO}_{4}$ was treated in such a way that the contributions above $0.5 \mathrm{~V}$ due to the $\mathrm{OH}$ adsorption/desorption (the butterfly peak) were eliminated, and only the charge of the double layer is remaining. The resulting curve was subtracted to those on Fig. 8, separating the positive and the negative scans. The results are shown in Fig. 9. Discarding the contributions of the butterfly peaks makes easier to observe the net oxidation currents due to the GA oxidation, which otherwise would be masked by the $\mathrm{OH}$ adsorption/desorption. Fig. 9 displays, independently of the sweep rate, a reversible peak centered in $0.47 \mathrm{~V}$ which must be associated to the adsorption/desorption process of the glycolate anion. On the other hand, the lower the scan rate is, the higher the net oxidation current above $0.6 \mathrm{~V}$. In this treatment, high sweep rates favored the thermodynamic 
adsorption process as the main features in the voltammogram, while low potential scans leads to kinetics controlled processes become more important.

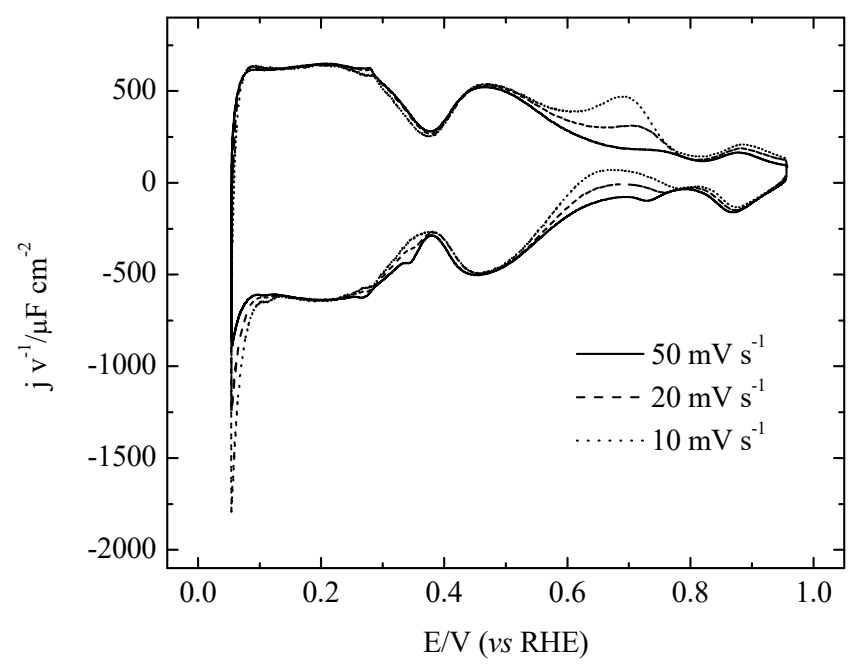

Figure 8. Cyclic voltammograms recorded at the Pt(111) electrode at different sweep rates. Currents are normalized by the sweep rate to maintain constant the adsorption processes and differentiate the kinetic contributions. Test solution: $10^{-3} \mathrm{M} \mathrm{GA}$ in $0.1 \mathrm{M}$ $\mathrm{HClO}_{4}$.

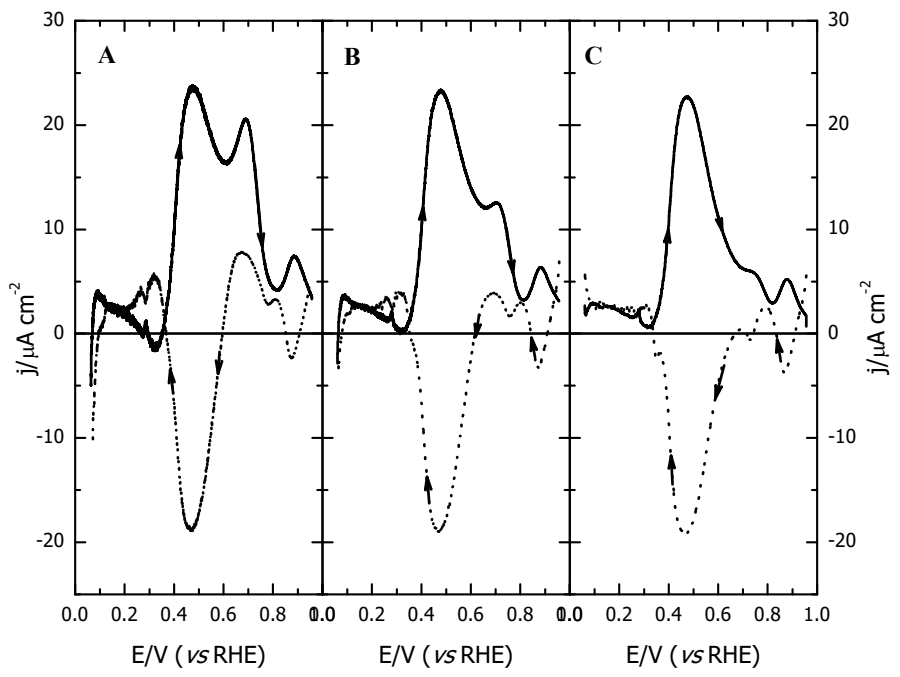

Figure 9. Curves resulted of the subtraction of the $\operatorname{Pt}(111)$ on $0.1 \mathrm{M} \mathrm{HClO}_{4}$ voltammogram, without the butterfly contribution, to the cyclic voltammograms recorded in $0.1 \mathrm{M} \mathrm{HClO}_{4}+10^{-3} \mathrm{M} \mathrm{GA}$ at different sweep rates: (A) $10 \mathrm{mV} \mathrm{s}^{-1}$, (B) $20 \mathrm{mV} \mathrm{s}^{-1}$ and (C) $50 \mathrm{mV} \mathrm{s}^{-1}$.

Fig. 10 shows voltammetric curves measured for the $\operatorname{Pt}(111)$ electrode in $0.1 \mathrm{M}$ $\mathrm{HClO}_{4}$ solutions, pure and with 10 additions of GA and recorded at a sweep rate of 50 $\mathrm{mV} \mathrm{s}^{-1}$. As mentioned before, high sweep rates are required to discriminate thermodynamic processes, thus mainly adsorption/desorption states are observed in the 
range of potentials studied. Within the hydrogen adsorption region (at $\mathrm{E}<0.3 \mathrm{~V}$ ), the voltammograms recorded in the different solutions overlap nicely, which indicates an excellent reproducibility. This behavior strongly suggests that no species other than adsorbed hydrogen are present at the surface of the $\mathrm{Pt}(111)$ electrode and proves that the oxygen content in the electrolyte is rather low. The charge associated to the anion adsorption grows and shifts in the negative direction when the bulk concentration of GA increases, becoming a sharp spike that make up the well known 'butterfly' appearance, characteristic for (bi)sulfate [24], acetate [21,22] the chloride adsorption [25] at the $\mathrm{Pt}(111)$ electrode surface. For solutions with GA concentrations higher than $5 \times 10^{-4} \mathrm{M}$, the CVs recorded display good symmetry indicating good reversibility of the adsorption/desorption phenomena. The performed measurements at lower sweep rate (Fig. 8) pointed out that the irreversibility observed for solutions with low GA concentrations is due to a kinetic process and not by a slow mass transport to the surface.

Further thermodynamic studies can be carried out from CVs displayed in Fig. 7 for the GA adsorption at the $\mathrm{Pt}(111)$ electrode surface, and the results can be compared with those present in the literature for the adsorption of other anions [24,25].

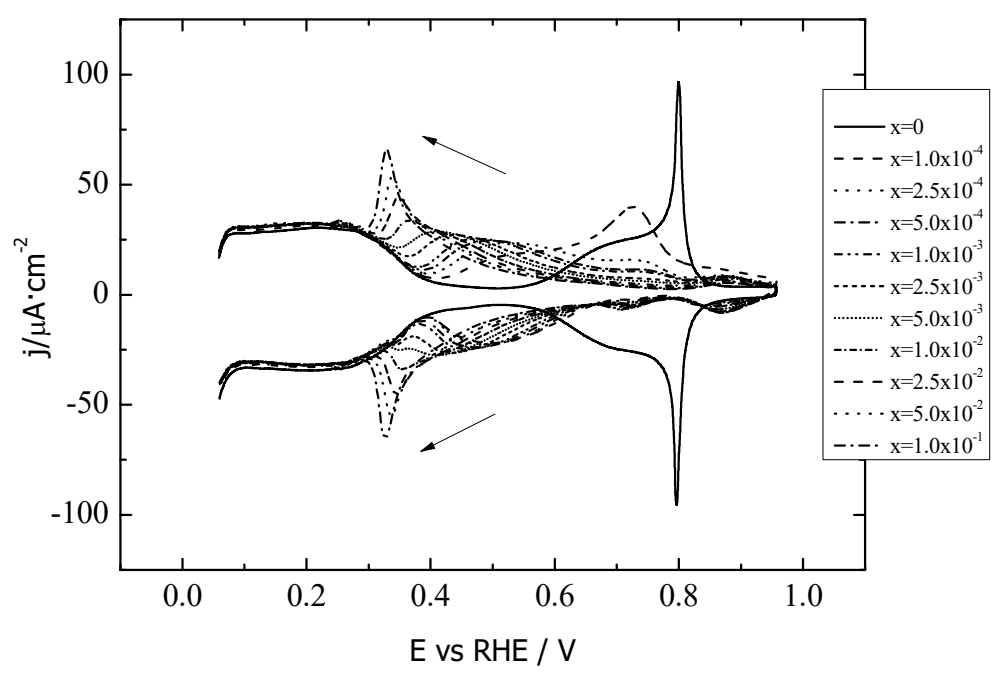

Figure 10. Cyclic voltammograms recorded at the $\mathrm{Pt}(111)$ electrode in $0.1 \mathrm{M} \mathrm{HClO}_{4}+x$ $\mathrm{M}$ GA. Sweep rate, $50 \mathrm{mV} \mathrm{s}^{-1}$. Arrows indicate directions in which the current increases with the bulk GA concentration.

\section{Acknowledgments}

The work was carried out under the financial support by the MICINN (project No. CTQ2010-16271). N.A.B. thanks the fellowship grant 2012/01040-3, São Paulo Research Foundation (FAPESP). 


\section{References}

1. J. Friedl, U. Stimming, Electrochim. Acta, 101, 41 (2013)

2. J.P. Busalmen, A. Esteve-Nuñez, J.M. Feliu, Approach to microbial fuelcells and their applications in A. Wieckowski and J.K. Norskov (Eds.) Fuel Cell Science: theory, fundamentals and biocatalysis. J. Wiley \& Sons, 2010, Chapter 8.

3. C. Lamy, S. Rousseau, E. Belgsir, C. Coutanceau, J. Leger, Electrochim. Acta, 41, 3901(2004).

4. S. Russeau, C. Coutanceau, C. Lamy, J.M. Leger, J. Power Sources, 158, 18 (2006).

5. F. Colmati, G. Tremiliosi-Filho, E.R. Gonzalez, A. Berna, E. Herrero, J.M. Feliu, Faraday Disc. 140, 379 (2008).

6. J. Souza-Garcia, E. Herrero, J.M. Feliu, ChemPhysChem, 11, 1391 (2010).

7. T. Iwasita, E. Pastor, Electrochim. Acta, 29, 531 (1994).

8. J.M. Orts, A. Fernandez-Vega, J.M. Feliu, A. Aldaz, J. Clavilier, J. Electroanal. Chem., 290, 119 (1990).

9. J.M. Orts, J.M. Feliu, A. Aldaz, J. Electroanal. Chem., 323, 303 (1992).

10. C. Korzeniewski, V. Climent, J.M. Feliu, Electrochemistry at platinum single crystal electrodes, in A.J Bard and C.G. Zoski (Eds.) Electroanalytical Chemistry, a series of advances, vol 24. CRC Press (2012), Chapter 2.

11. F. Cases, J.L. Vázquez, J.M. Perez and A. Aldaz, J. Electroanal. Chem., 310, 403 (1991).

12. S.C.S. Lai and M.T.M. Koper, Faraday Discuss., 140, 399 (2008).

13. A. Berná, V. Climent, J.M. Feliu, Electrochemistry Communications, 9, 2789 (2007).

14. J.Clavilier, D. Armand, J. Electroanal. Chem., 199, 187 (1986).

15. G. Inzel and G. Horanyi, Acta Chim. Acad. Sci. Hung., 101, 229 (1979).

16. G. Pierre, A. Ziade and M. El Kordi, Electrochim. Acta., 32, 601 (1987).

17. E. Bourier-Charbonnier, B. Beden, J.M. Leger and C. Lamy, 34th ISE Meeting, Erlangen, Germany (1983). Abstr. No. 05160.

18. S.-C. Chang, L.-W. H. Leung and M. J. Weaver, J. Phys. Chem., 94, 6013 (1990).

19. J.Clavilier and S.G. Sun, J. Electroanal. Chem., 199, 471 (1986).

20. S.G. Sun and J.Clavilier, J. Electroanal. Chem., 236, 95 (1987).

21. A. Rodes, E. Pastor, T. Iwasita, J. Electroanal. Chem., 376, 109 (1994).

22. J.M. Orts, A. Rodes, J.M. Feliu, J. Electroanal. Chem., 434, 121 (1997).

23. A. Berná, A. Rodes and J.M. Feliu, Electrochim. Acta., 49, 1257 (2004).

24. E. Herrero, J. Mostany, J.M. Feliu and J. Lipkowski, J. Electroanal. Chem., 534, 79 (2002).

25. N. Garcia-Araez, V. Climent, E. Herrero, J.M. Feliu and J. Lipkowski, J. Electroanal. Chem., 576, 33 (2005). 